\title{
Cecília Vicuña, o baile de los chinos e as sementes ancestrais de futuro ${ }^{1}$
}

\author{
Eleonora Frenkel Barretto ${ }^{2}$ \\ Universidade Federal de Santa Catarina - UFSC, Florianópolis, Santa Catarina, Brasil
}

Resumo: O artigo apresenta "Tugar Tugar salir a buscar el sentido perdido", uma oficina realizada por Cecília Vicuña com o objetivo de trazer à comunidade de Caleu-Chile a escuta do saber ancestral incorporado na prática do baile de los chinos. A análise propõe pensar a transmissão da memória dessa performance como gesto político que visa a descolonização do pensamento e o enfrentamento dos históricos processos de banimento a que foi submetido o repertório das civilizações pré-coloniais. Fundamentam a leitura o conceito de performance como "prática incorporada", de Schechner, as reflexões sobre arquivo, repertório e memória, por Taylor; as teses sobre história e memória, de Benjamin, passando pela crítica de Didi-Huberman; os processos de singularização subjetiva pensados por Guattari. Enfrenta-se a discussão entre o conceito de hibridação, de Canclini, e o de ch'ixi, desenvolvido por Cusicanqui, para pensar as tensões e antagonismos implicados na sobrevivência dos bailes chinos.

Palavras-chave: Cecília Vicuña; performance; memória; hibridação; ch'ixi.

Title: Cecília Vicuña, the ancient tradition of "bailes chinos" and the seeds of the future

Abstract: The article presents "Tugar Tugar salir a buscar el sentido perdido", a workshop conducted by Cecilia Vicuña with the aim of bringing to the community of Caleu-Chile the listening of the ancestral knowledge incorporated in the practice of the baile de los chinos. The analysis proposes to think of the transmission of the memory of this performance as a political gesture aimed at the decolonization of thought and the confrontation of the historical processes of banishment to which the repertoire of pre-colonial civilizations was subjected. Schechner's concept of performance as "incorporated practice" is one of the foundations of the analysis, as Taylor's reflections on archives, repertoire and memory, Benjamin's theses on history and memory, passing through Didi-Huberman's criticism, the processes of subjective singularization thought by Guattari. There is a discussion between Canclini's concept of hybridization and that of $c h^{\prime} i x i$, developed by Cusicanqui, to think about the tensions and antagonisms involved in the survival of bailes chinos.

\footnotetext{
${ }^{1}$ Uma primeira versão deste artigo foi apresentada como comunicação oral no XIV Seminário Nacional de Literatura, História e Memória e V Congresso Internacional de Pesquisa em Letras no Contexto Latino-Americano, e aparece publicada nos anais do evento com o título "Cecília Vicuña e a escuta de uma sabedoria ancestral e futura". In: Anais do Seminário Nacional de Literatura, História e Memória, Cascavel/UNIOESTE, 2020. Disponível em: https://midas.unioeste.br/sgev/eventos/literaturahistoriaememoria/anais (Acesso: 18/12/2020) ${ }^{2}$ Doutora em Literatura pela Universidade Federal de Santa Catarina (UFSC). Professora Adjunta do curso de Letras-Espanhol da Universidade Federal de Santa Catarina (UFSC). Orcid: https://orcid.org/0000-0002-3279-2546. E-mail: eleonora.frenkel@ufsc.br
} 
Keywords: Cecília Vicuña; performance; memory; hybridization; ch'ixi.

Onde está o futuro do ouvido do mundo? Caleu: ser transformado (Mapuche)

Memória, sobrevivência, saberes e práticas incorporadas

Dou início a este texto com um poema visual de Cecilia Vicuña, que está em seu livro PALABRARmás, publicado por primeira vez em 1984, em Buenos Aires, e, posteriormente em 2005, em Santiago de Chile. Em 2017, foi traduzido por Ricardo Corona e publicado pela editora Medusa, em Curitiba:

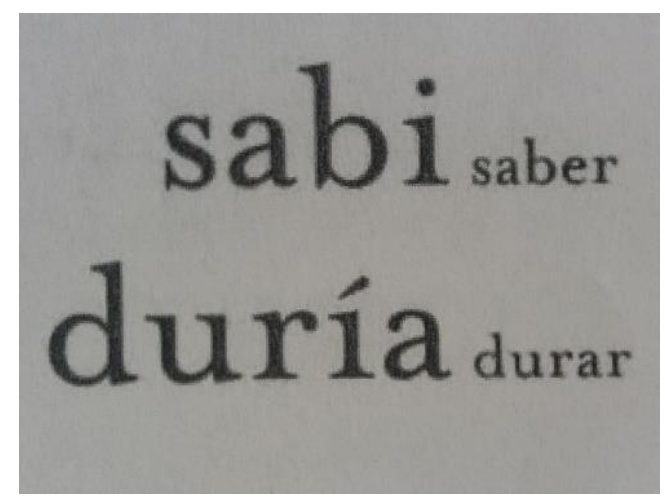

Fonte: VICUÑA, 2005, p. $75 .^{3}$

O poema suscita uma relação entre a sabedoria e a duração no tempo, ou, entre o saber e a memória, se o pensamos com Henri Bergson (2000), que define a memória como sobrevivência das imagens passadas que se misturam à percepção do presente, e que destaca a existência de duas memórias: a que imagina, representa ou encena o passado, e a que repete, que resulta do hábito e da repetição; onde entrariam, por sua vez, as formas de transmissão e continuidade do conhecimento que, desde já, entende-se para além de seus registros escritos e se amplia a diversas formas de conhecimento incorporado, tais como língua falada, dança, ritual, esportes, culinária; ou seja, o que Diana Taylor chama de repertório e que, no contexto da colonização nas américas, foi desvalorizado, deslegitimando suas práticas como formas válidas de conhecimento, em detrimento do saber escrito, ou do arquivo, um conjunto de materiais supostamente duradouros (textos, documentos, edifícios, ossos) a partir do qual se definem as epistemologias válidas. Como diz Taylor (2013, p. 47):

\footnotetext{
${ }^{3}$ SABE saber

DORIA durar (Vicuña, 2017, p. 79).
} 
"O que mudou com a conquista não foi que a escrita deslocou a prática incorporada [...], mas o grau de legitimação da escrita em relação a outros sistemas epistêmicos e mnemônicos." A partir dessa reflexão, procura-se perceber as tensões entre arquivo e repertório, bem como ampliar a concepção de saber para a memória incorporada, incluindo os atos de transferência não verbal de conhecimento.

O poema se constrói a partir de um procedimento que Vicuña chama de palavrar ou palabrir, um jogo que consiste em abrir o corpo das palavras, desmontá-las e remontá-las para dar a ver novas significações. Esse dar a ver traz o impulso da imaginação e da invenção de novos possíveis, a partir de um olhar sensível e atento, motivado a provocar renascimentos e redescobertas, de modo que se possam reabrir os sentidos. Segundo Vicuña (2005, p. 24): "Palabrir es vivir en las palabras, experimentarlas como si fueran recién nacidas, y ellas y nosotros llegáramos al encuentro por primera vez."4 $\mathrm{E}$, ainda: "Palabrar más o palabrir/es armar y desarmar palabras/para ver qué tienen/que decir." (VICUÑA, 2005, p. $54)^{5}$

Essa reabertura se dá em um presente que atualiza o passado, o que nos remete ao problema do tempo histórico, tal qual o apresenta Didi-Huberman, a partir de Walter Benjamin: o da "colisão de um presente ativo com seu passado reminiscente." (DIDIHUBERMAN, 2011a, p. 61) A reminiscência se refere ao que fica na memória, o que permanece ou o que sobrevive. O esquecimento também constrói a história, pois é nos silêncios que reside o resíduo do discurso que se faz hegemônico, e é na latência dessa memória solapada que se pode fazer eclodir o abalo das hegemonias. Não como um retorno a um passado idealizado, mas como uma urgência do presente em repensar seus passos e retraçar seus caminhos. Benjamin (1994, p. 224) apontou que "articular historicamente o passado não significa conhecê-lo 'como ele de fato foi'. Significa apropriar-se de uma reminiscência, tal como ela relampeja no momento de um perigo."

Ao desdobrar a citação, pergunto: que memórias se fazem presentes na iminência da catástrofe? Relaciono a reflexão sobre a memória com o poema de Vicuña, para pensar os saberes que, embora silenciados, duram no tempo e cuja escuta se revela necessária, principalmente quando os saberes hegemônicos evidenciam sua falência, o que evoca, ainda, as tensões e disputas de que é feita a história.

O pensamento sobre a memória, por sua vez, traz as noções de sobrevivência e anacronismo. Como destaca Didi-Huberman, esta vez a partir de Aby Warburg, a sobrevivência ocorre "cuando se hace aparecer la larga duración de un pasado latente. ${ }^{6 "}$ (DIDI-HUBERMAN, 2011, p. 144) Como a sabedoria no poema de Vicuña, que sabe durar, persistir no tempo. Nesse sentido, quero pensar o baile de los chinos, com o qual Vicuña

\footnotetext{
4 "Palabrir é viver nas palavras, experimentá-las como se fossem recém-nascidas. Nós e elas chegando ao encontro pela primeira vez." (Vicuña, 2017, p. 25).

5 "Palavrar mais ou palabrir/é montar e desmontar palavras/para ver o que elas têm/a dizer." (Vicuña, 2017, p. 56).

6 "Quando se evidencia a longa duração de um passado latente." (Tradução da autora)
} 
trabalha desde 1995, como uma sobrevivência, um saber que perdura, a despeito dos obstáculos que são impostos à sua transmissão. E, como mostra a artista no documentário Tugar Tugar, onde registra seu trabalho de sensibilização da percepção das novas gerações para esse saber ancestral que estava silenciado há ao menos 30 anos na comunidade de Caleu - Chile: os chinos são sábios que levam sua sabedoria em sua música, em sua dança e em seu corpo.

É a partir do presente que buscamos o conhecimento histórico sobre o baile de los chinos, é o tempo do agora que se preenche com a densidade da memória para pensar o que foram e o que são esses bailes e, mais do que isso, o que faz com que relampejem no presente e reverberem possibilidades de criação de outros espaços (heterotopias ${ }^{7}$ ) onde não prevaleçam somente os saberes impostos pela colonização e as subjetividades capitalísticas ${ }^{8}$. Nesse sentido, o conhecimento histórico se compreende como "proceso al revés del orden cronológico, un retroceso en el tiempo, un anacronismo. ${ }^{9 "}$ (DIDI-HUBERMAN, 2011, p. 54-55)

Observar as luminescências do passado no presente e pensar o futuro, ou, escutar a ancestralidade e sua latência no tempo do agora para pensar o amanhã são ações que demonstram uma compreensão do pensamento sobre a história como enfretamento de tempos heterogêneos e que deslocam a linearidade positiva do discurso do progresso e do avanço de um modelo de civilização. Didi-Huberman (2011a, p. 60) fala em "repensar nosso próprio 'princípio esperança' [referência a E. Bloch, Le príncipe esperance - 1938-1959] através do modo como o Outrora encontra o Agora para formar um clarão, um brilho, uma constelação onde se libera alguma forma para nosso próprio Futuro." Essa perspectiva concerne à imaginação e à política: "em nosso modo de imaginar jaz fundamentalmente uma condição para nosso modo de fazer política." (DIDI-HUBERMAN, 2011, p. 60-61)

Na trajetória de Cecilia Vicuña, arte e ativismo caminham juntas, seja na imaginação poética de novas significações, no jogo de palavrar, seja numa oficina artístico-pedagógica que se propôs a imaginar o baile chino novamente na comunidade de Caleu, instigando a curiosidade e a imaginação das crianças para tal, ou, ainda, na ampla diversidade de trabalhos que desenvolve no campo da poesia e das artes visuais, dedicados a temas como a ditadura militar no Chile, a preservação ambiental, os saberes ancestrais, como os quipus, as línguas e textualidades de povos originários.

\footnotetext{
7 Segundo Foucault (2013, p. 28): as heterotopias "são a contestação de todos os outros espaços, uma contestação que pode ser exercida de duas maneiras: [...] criando uma ilusão que denuncia todo o resto da realidade como ilusão, ou, ao contrário, criando outro espaço real tão perfeito, tão meticuloso, tão bem disposto quanto o nosso é desordenado, mal posto e desarranjado."

${ }^{8}$ A expressão é de Felix Guattari, que afirma que "o indivíduo está na encruzilhada de múltiplos componentes de subjetividade" (GUATTARI e ROLNIK, 1996, p. 34) e que a subjetividade capitalística é uma subjetividade mais ampla que se (re)produz nas sociedades capitalistas e seu movimento globalizante.

9 "Processo ao contrário da ordem cronológica, um retrocesso no tempo, um anacronismo." (Tradução da autora)
} 
Repertório e processos de singularização subjetiva

Nessa poética em que a memória procura ativar no presente uma potência de futuro, destaca-se a imaginação de contraespaços (heterotopias) e a promoção de processos disruptores no campo da produção do desejo. Como explica Foucault (2013), a heterotopia justapõe espaços que seriam incompatíveis e cria uma singular relação com o tempo, produz uma heterocronia, seja pela utopia de eternidade, seja pelo próprio apagamento do tempo. Nesse sentido, estariam, por exemplo, a irrupção do tempo da festa no ordenamento autoritário do espaço da escola, que se pode observar no trabalho desenvolvido por Vicuña em Caleu; ou a escultura denominada "otoño", que preencheu, em Junho de 1971, toda uma sala do Museu Nacional de Belas Artes (Santiago) com folhas de árvores coletadas pela artista em sacolas plásticas no parque florestal, configurando uma obra conceitual, onde o próprio gesto de coletar as folhas se torna a obra, uma "escultura vivente". ${ }^{10}$ Os espaços da escola e do museu são contestados e os tempos subvertidos: o tempo produtivo pelo tempo da festa, a efemeridade do outono guardada na eternização do espaço do museu.

Contraespaços e contratempos que propõem imaginar outras configurações da organização da vida, num sentido que se poderia aproximar às possibilidades de desvios e de reapropriações que afrontam a serialização de indivíduos no desenvolvimento da subjetividade capitalística. Na análise de Félix Guattari e Suely Rolnik, a subjetividade consiste em uma produção que, nas sociedades capitalísticas, tende a bloquear processos de singularização e instaurar processos de individuação:

Os homens, reduzidos à condição de suporte de valor, assistem, atônitos, ao desmanchamento de seus modos de vida. Passam então a se organizar segundo padrões universais, que os serializam e os individualizam. [...]

É, portanto, num só movimento, que nascem os indivíduos e morrem os potenciais de singularização. (GUATTARI e ROLNIK, 1996, p. 38)

Haveria, entretanto, dois extremos entre os quais oscila o modo pelo qual os indivíduos vivem essa subjetividade: uma relação de alienação e opressão, onde o indivíduo se submete à subjetividade tal qual a recebe, ou uma relação de expressão e de criação, onde ele se reapropria dos componentes da subjetividade e produz um processo de singularização (Cf. GUATTARI e ROLNIK, 1996, p. 33). A singularidade se refere às diferentes maneiras de existir, e difere da identidade que as reduz a um mesmo quadro de referência identificável, tal como se observa na cultura de massa, associada à serialização de indivíduos iguais e ao empobrecimento de processos de vida social, em sua riqueza e diferenciação, o que resulta em que "tradições milenares de um certo tipo de relação social e de vida cultural são rapidamente varridas do planeta." (GUATTARI e ROLNIK, 1996, p. 40)

10 "Es lo que se llama vivir la escultura o hacer una escultura viviente porque sinceramente la escultura soy yo" (VICUÑA, 1973, n.p.) 
A ruptura do complexo industrial da subjetivação se daria, nessa reflexão, não apenas no plano da economia política, mas também no da economia subjetiva, na produção do desejo, entendido como "todas as formas de vontade de viver, de vontade de criar, de vontade de amar, de vontade de inventar uma outra sociedade, outra percepção de mundo, outros sistemas de valores." (GUATTARI e ROLNIK, 1996, p. 215) Como explica Rolnik:

O termo singularização é usado por Guattari para designar os processos disruptores no campo da produção do desejo: trata-se dos movimentos de protesto do inconsciente contra a subjetividade capitalística, através da afirmação de outras maneiras de ser, outras sensibilidades, outra percepção, etc. (GUATTARI e ROLNIK, 1996 p. 45)

Esses processos de singularização, autonomização ou revolução molecular, como os denomina Guattari, configuram importantes fatores de resistência política e ocorrem a partir dos movimentos sociais e de grupos minoritários que ousam produzir modos de subjetividade originais e singulares (processos de singularização subjetiva), que enfrentam a serialização, construindo "seus próprios tipos de referências práticas e teóricas, sem ficar nessa posição constante de dependência do poder global, a nível econômico, a nível do saber, a nível técnico, a nível das segregações, dos tipos de prestígio que são difundidos." (GUATTARI e ROLNIK, 1996, p. 46) Como modo de escapar aos sistemas modelizantes da subjetividade capitalística, pode-se pensar na oposição aos modos dominantes de temporalização e espacialização, na recusa de certo ritmo nos processos de trabalho assalariado, na relação com o tempo produzida pelo próprio grupo, na música ou na dança, por exemplo.

Assim, o baile de los chinos, como memória ancestral que se ativa no presente de Caleu, desloca-se como traço arcaico a ser resgatado para se pensar como devir singular, como diferenciação dos saberes incorporados naquela comunidade, como produção de desejos que se chocam contra o "muro da subjetividade capitalística" (GUATTARI e ROLNIK, 1996, p. 50) quando, por exemplo, as crianças se organizam coletivamente para aprender a tocar a flauta e dançar, e não para consumir brinquedos industrializados.

\section{Baile de los chinos: justaposição e enfrentamento de diferenças}

Cecilia Vicuña e James O'Hern idealizaram $O y s i^{11}$, um projeto de escuta da ancestralidade para pensar o futuro, que se configura como uma plataforma educacional para a confluência das artes, ciências e culturas orais, onde se reúnem artistas de diversas áreas, pesquisadoras, cientistas e ativistas. O nome Oysi é um neologismo que poderia

\footnotetext{
${ }^{11}$ Para saber mais, acessar: http://oysi.org/es/
} 
significar em espanhol "¿Oyes? ¡Sí!"12 ou “¿Hoy? ¡Sí!” 13. Ambos os jogos de palavras remetem à proposição da escuta e da ação imediata, a urgência do tempo do agora de reconfigurar suas memórias e subjetividades. O nome Oysi também propõe uma homenagem a Oisín, poeta legendário da Irlanda, cujo nome significa "jovem cervo" no idioma gaélico antigo. Segundo Vicuña e O'Hern, o cervo é considerado o mais alto modelo do comportamento humano em múltiplas culturas do mundo porque dá sua vida pelo bem dos outros.

Por siglos, las voces de las culturas orales han sido ignoradas mientras que nuestro mundo continúa en un camino de auto destrucción. Para cambiar este rumbo debemos recuperar el potencial de nuestra verdadera humanidad necesitamos una nueva visión, y oír a los que han mantenido viva la memoria de nuestras conexiones ancestrales. ${ }^{14}$ (VICUÑA e O'HERN, oysi.org)

Faz-se necessário conhecer a história do processo de ocupação territorial e colonização das civilizações pré-colombianas para entender ao que se submeteram os amplos repertórios das culturas orais. Em geral, mais do que ignoradas, foram banidas. Muitos saberes que arderam nas fogueiras inquisitoriais e padeceram nas marcas do chicote não tiveram a oportunidade de dar continuidade a seus modos de compreender e organizar a vida. Embora não se possa encontrá-los em nenhum estado de pureza, abrir-se a essa escuta é o que se aponta como proposta.

Tugar Tugar, salir a buscar el sentido perdido é um filme de Cecilia Vicuña (2011) que registra uma oficina homônima realizada pela artista em 1995, em uma escola rural na localidade de Caleu-Chile, em colaboração com os etnomusicólogos Claudio Mercado Muñoz e José Perez de Arce, ambos fundadores do grupo musical La Chimuchina, ${ }^{15}$ que investiga sonoridades pré-hispânicas e sua continuidade em povos e comunidades onde seguem se realizando intervenções performáticas de origem pré-colombiana. Como se explica na apresentação da origem do grupo musical, em sua página web:

En las tradiciones aún existentes, en cientos de festividades desarrolladas en diversos territorios de América, se fueron encontrando claves de la performática de estos antiguos sonidos. El sonido dentro del paisaje cultural, en fiestas devocionales, en los ritos del pueblo, en las prácticas de curación, y en muchos momentos de la vida social vernacular americana. La música-asimismo-vinculada

\footnotetext{
12 "Escutas? Sim!" (Tradução da autora).

13 "Hoje? Sim!" (Tradução da autora).

14 "Por séculos, as vozes das culturas orais foram ignoradas, enquanto nosso mundo segue um caminho de autodestruição. Para mudar esse rumo, devemos recuperar o potencial de nossa verdadeira humanidade, precisamos uma nova visão e ouvir àqueles que mantiveram viva a memória de nossas conexões ancestrais." (Tradução da autora)

${ }^{15}$ Para conhecer mais, acessar: https://www.chimuchina.org/
} 
al desplazamiento, al vestuario festivo, al paisaje y a múltiples estímulos sensoriales. ${ }^{16}$ (https://www.chimuchina.org/origen-y-concepto)

O objetivo final da oficina Tugar Tugar, apresentado em depoimento de Vicuña no mencionado documentário, é provocar nas crianças a compreensão de que a poesia e o espírito do lugar já estão nelas e fazê-las perceber que há nessa localidade uma sabedoria ancestral e ao mesmo tempo futura, com a qual se encontrarão ao se abrir a si mesmas. Através de diversas práticas de leitura, desenho, escuta de sons da natureza e diálogos sobre a memória de Caleu, as crianças pouco a pouco se reencontram com uma antiga prática incorporada que seus pais e avós haviam abandonado: o baile de los chinos.

Tombado como patrimônio cultural imaterial pela UNESCO, o baile de los chinos consiste em irmandades de músicos que manifestam sua fé através da música, da dança e do canto, em festas comemorativas. É uma expressão cultural praticada em diversas regiões do Chile (do Norte Chico à Zona Central), organizada principalmente por homens das zonas rurais e caracterizada pela execução de saltos e flexões de pernas ao ritmo de uma música instrumental isométrica, que se interpreta com instrumentos percussivos e flautas de origem pré-colombiano. $\mathrm{O}$ grupo é acompanhado por dançarinas e pelo poeta alferes que canta coplas de tema religioso, memorizadas ou improvisadas. Como se destaca no verbete "el baile chino", na página web da UNESCO:

Los bailes chinos son instrumento de participación en la vida social, que prestigian a los que participan en ellos. Constituyen modelos de integración y cohesión sociales que cuentan con la adhesión de casi totalidad de las comunidades locales y, además, confieren un sentimiento de identidad y solidaridad a quienes los practican. ${ }^{17}$ (https://ich.unesco.org/es/RL/el-baile-chino-00988 )

Da perspectiva de Vicuña e Muñoz, o baile de los chinos é um ritual bem estruturado, com a dança, o som e a hiperventilação provocada pelo sopro constante da flauta. Trata-se de uma tecnologia espiritual, cultural, ética, social e poética, uma obra de arte que merece ter continuidade. ${ }^{18}$ Enquanto práticas incorporadas, ou, comportamentos restaurados, os bailes são pensados, com Richard Schechner (2011, n.p.), como performances rituais cuja autoria se atribui a um "anônimo coletivo" ou à tradição, e que desempenham todas as

\footnotetext{
16 "Nas tradições ainda existentes, em centenas de festividades desenvolvidas em diversos território da América, encontraram-se códigos da performática dessas antigas sonoridades. 0 som dentro da paisagem cultural, em festas devocionais, nos ritos dos povos, nas práticas de cura, e em muitos momentos da vida social vernacular americana. A música - igualmente - vinculada ao deslocamento, ao vestuário festivo, à paisagem e a múltiplos estímulos sensoriais." (Tradução da autora)

17 "Os bailes chinos são instrumento de participação na vida social, que prestigiam seus participantes. Constituem modelos de integração e coesão social que contam com a adesão da quase totalidade das comunidades locais e, além disso, conferem um sentimento de identidade e solidariedade a quem os praticam." (Tradução da autora)

${ }^{18}$ Diálogo entre Vicuña e Muños no filme Oysi, la escuela del oír (2018).
} 
funções elencadas pelo crítico: entreter, construir algo belo, formar identidade, construir comunidade, curar, ensinar, lidar com o sagrado e o profano.

É importante compreender um pouco mais sobre a história dessa performance no contexto colonial e pós-colonial e refletir sobre a complexidade dos conflitos implicados em seu processo de duração no tempo, principalmente no enfrentamento entre sua origem précolonial e a instituição católica. Como explica Muñoz (2002), os primeiros antecedentes dos bailes chinos se encontram nas flautas do chamado "Complejo Aconcagua", cultura que viveu na zona central do Chile entre o ano 900 e 1400 d.C. Durante a conquista e a colônia, há notícias desse ritual em crônicas de viajantes. Os aportes indígenas encontram-se na música instrumental, nos tipos de instrumento, na dança, na relação do ritual com a obtenção de estados especiais de consciência, na comunicação com as divindades. Essa alteração no estado de consciência implica uma mudança drástica na percepção do universo e na relação estabelecida com ele. Esse estado de transe místico permite acessar uma relação direta com as divindades. Os elementos que permitem essa mudança na percepção são a hiperventilação, a saturação auditiva, a repetição rítmica, o esforço físico de dançar e tanger, de forma contínua e repetitiva, a pressão psicológica, as palavras do alferes, a significação do ritual.

Por outro lado, surgem os aportes hispânicos, como o canto do alferes, a presença das sagradas escrituras, as imagens católicas e seu calendário litúrgico. As comunidades que praticam atualmente as performances não são indígenas, pois a zona central do Chile foi a área onde a ocidentalização se efetivou com maior rapidez, eliminando a população indígena e absorvendo seus sobreviventes como mestiços, os atuais camponeses e pescadores. Segundo Muñoz (2002), entretanto, a população soube conservar seu substrato indígena naquilo que é mais importante para sua sobrevivência: sua ritualidade. Essa preservação não ocorre sem conflito, uma vez que a igreja católica, unida ao poder político e repressivo do Estado, procura histórica e sistematicamente fazer desaparecer essa tradição, ou, mediante sua impossibilidade, busca torná-la católica, torná-la "menos pagã", estruturar as festas de modo que o ritual em geral seja católico e que os chinos sejam apenas uma parte dele. Entretanto, como destaca Muñoz:

Es importante mencionar que la estética musical de la música instrumental de los bailes chinos es absolutamente ajena y contraria a la europea, es una manifestación que, en lo estrictamente musical, está relacionada a las poblaciones indígenas que habitaban la zona central de Chile antes de la llegada de los españoles. ${ }^{19}$ (MUÑOZ, 2002, n.p.)

\footnotetext{
19 “É importante mencionar que a estética musical da música instrumental dos bailes chinos é absolutamente alheia e contrária à europeia, é uma manifestação que, no estritamente musical, está relacionada com as populações indígenas que habitavam a zona central do Chile antes da chegada dos espanhóis" (Tradução da autora).
} 
Desde a invasão territorial no século XV, as práticas incorporadas ameríndias são banidas e submetidas aos ditames do catolicismo, mas no caso específico dos bailes chinos, segundo dados levantados por Muñoz, é ao final do século XIX que as proibições se tornam mais severas por parte da igreja, com repressão policial. O levantamento de informações se faz mais claro a partir de 1950, evidenciando os esforços de apropriação das festas e estruturação conforme seus parâmetros, como no exemplo dos cartazes fixados nos muros das paróquias da zona do valle del Limarí, onde se lê o decreto papal e episcopal que proíbe na igreja o uso de tambores, flautas ou qualquer outro instrumento que não seja o órgão e o harmônio.

\section{Prohibición}

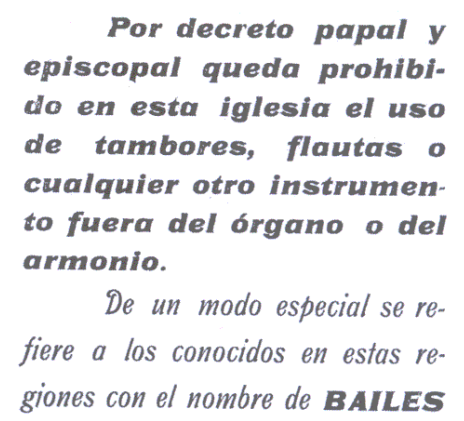

De un modo especial se refiere a los conocidos en estas regiones con el nombre de BAILES

\section{EL ARZOBISPO}

Figura 3: Cartaz colocado nos muros de todas as paróquias da zona do valle del Limarí, na década de 1950. Fonte: MERCADO MUÑOZ, 2002, n. p.

Ainda assim, Muñoz ressalta que a batalha com os bailes chinos tem sido dura e que, embora o ritual tenha sido incorporado ao calendário católico e esta seja a fé que se professa atualmente nas celebrações, as características xamânicas seguem de algum modo presentes. O antropólogo destaca que no final do século XIX ainda se conservavam os cantos dos alferes em língua nativa na região do vale de La Ligua e que até 1922, os bailes chinos de Andacollo eram sociedades secretas, onde se admitiam apenas os iniciados, evidenciando esforços de resistência e preservação de autonomia.

Vale lembrar a análise que Diana Taylor faz da desvalorização de performances nativas desde o momento inaugural do colonialismo nas Américas. Segundo Taylor (2013, p. 69), antes da conquista, "a escrita e a performance incorporada têm frequentemente funcionado juntas para organizar as camadas de memórias históricas que constituem a comunidade", quer dizer, tanto a escrita (pictogramas) quanto as danças e as canções 
(areitos ${ }^{20}$ e cantares) operam de modo complementar na transferência da memória coletiva. A conquista impõe tanto a queima de manuscritos ${ }^{21}$ quanto a proibição das performances, demonstrada por editos proibitivos que se sucedem desde 1555, em particular no contexto mexica analisado por Taylor. ${ }^{22}$ Mas, como também destaca a pesquisadora, em que pesem todas as proibições, e a contragosto dos evangelizadores, essas práticas não estavam desaparecendo e, como ela anota, com certa ironia: "A performance das proibições parece tão ubíqua e contínua quanto as próprias práticas banidas. Nenhuma delas desapareceu." (TAYLOR, 2013, p. 81) Muito embora o pensamento colonialista hegemônico queira fazer dessas práticas algo primitivo, antigo ou anterior, tendo sido superadas pela hipervalorização do saber letrado e das formas escritas de transmissão do conhecimento, o que se revela é que "a expressão incorporada continua e, provavelmente, continuará a participar da transmissão do conhecimento social, da memória e da identidade pré e pósescrita." (TAYLOR, 2013, p. 45) Nesse sentido, Taylor destaca a relevância para os estudos culturais de "levar a performance a sério, considerando-a um sistema de aprendizagem, armazenamento e transmissão de conhecimento." (TAYLOR, 2013, p. 45)

A partir da leitura de Néstor García Canclini, poderíamos pensar na hibridação para caracterizar o baile chino como uma fusão de elementos pré-colombianos com aportes do novo-hispanismo colonial. Embora Canclini (2003, p. xviii) destaque que "hibridação não é sinônimo de fusão sem contradições", o conceito é definido pelo crítico como "processos socioculturais nos quais estruturas ou práticas discretas, que existiam de forma separada, se combinam para gerar novas estruturas, objetos e práticas." (CANCLINI, 2003, p. xix) A análise dos processos de hibridação procura dar conta da heterogeneidade nas relações interculturais e da elaboração das tensões entre as diferenças. As políticas de hibridação se apresentam como algo que serviu para "trabalhar democraticamente com as divergências, para que a história não se reduza a guerras entre culturas" (CANCLINI, 2003, p. xxvii) e, nesse sentido de pensar a hibridação como processo que evita a segregação, Canclini afirma que: "Podemos escolher viver em estado de guerra ou em estado de hibridação." (CANCLINI, 2003, p. xxvii) Parece-me que a despeito das diversas mesclas entre culturas, entre o tradicional e o moderno, ou, entre o culto e o popular, no campo artístico, a história tem dado inúmeros exemplos de que as fusões interculturais não tem sido capazes de superar o

20 "Areito, termo que designa música e dança. Areitos, do arauaque aririn, era usado pelos conquistadores para descrever um ato coletivo que envolvia canto, dança, celebração e culto, que reivindicava legitimidade não só estética, mas também sociopolítica e religiosa." (TAYLOR, 2013, p. 43) ${ }^{21}$ Ver, por exemplo, o Auto de fe de Maní (1562) .

22 "Um edito de 1555 chama atenção para a natureza continuada dessas práticas: 'Muito inclinados são os índios destas partes para danças e areitos e outras formas de regozijo que, desde seu paganismo, eles tinham o hábito de praticar.' [...] Em 1702, a batalha contra a performance idólatra continuava com novas proibições: 'Que não haja danças ou outras cerimônias que façam alusão ou referência às superstições do paganismo antigo.' E os editos se sucedem: 1768, 1769, 1770, 1780, 1792, 1796, 1808, 1813." (TAYLOR, 2013, p. 79) 
estado de guerra em que vivemos. Como diz Ailton Krenak em uma entrevista: ${ }^{23}$ "Nós estamos em guerra. O seu mundo e o meu mundo estão em guerra. Nossos mundos estão todos em guerra [...] Não tem paz em lugar nenhum. É guerra em todos os lugares, o tempo todo."

Silvia Rivera Cusicanqui faz uma crítica a essa noção de "hibridez", proposta por Canclini, pois destaca nela a metáfora genética que traz a conotação de esterilidade:

La mula es una especie híbrida y no puede reproducirse. La hibridez asume la posibilidad de que de la mezcla de dos diferentes, pueda salir un tercero completamente nuevo, una tercera raza o grupo social capaz de fusionar los rasgos de sus ancestros en una mezcla armónica $y$ ante todo inédita. ${ }^{24}$ (RIVERA CUSICANQUI, 2010, p. 70)

Na análise de Cusicanqui, a hibridação não daria conta da tensão e dos conflitos, criando uma falsa perspectiva de harmonia. Sua proposta é pensar a noção de $c h^{\prime} i x i^{25}$ que sugere a coexistência em paralelo de múltiplas diferenças culturais que não se fundem, mas se antagonizam ou se complementam. Cada uma se reproduz a si mesma, das profundezas do passado e se relaciona com as outras de forma litigiosa. ${ }^{26} \mathrm{O}$ "discurso fictício da hibridação" seria também uma forma de submissão do indígena contra a qual Cusicanqui propõe o ch'ixi, como algo que conjuga opostos sem submeter um ao outro, justapondo diferenças concretas que não tendem a uma comunhão sem problematizá-la. "Lo ch'ixi constituye así una imagen poderosa para pensar la coexistencia de elementos heterogéneos que no aspiran a la fusión y que tampoco producen un término nuevo, superador y englobante." ${ }^{27}$ (RIVERA CUSICANQUI, 2010, p. 7) Trata-se de uma forma de conjugar o

\footnotetext{
${ }^{23}$ Bolognesi, Luiz. Guerras do Brasil.Doc, 2018. Série documental em 5 episódios. Netflix. Episódio1: As guerras da conquista. Disponível em: https://www.youtube.com/watch?v=VeMISgnVDZ4 (Acesso $23 / 11 / 2020)$

24 "A mula é uma espécie híbrida e não pode se reproduzir. O hibridismo assume a possibilidade de que da mescla de dois diferentes possa sair um terceiro completamente novo, uma terceira raça ou grupo social capaz de fundir os traços de seus ancestrais em uma mescla harmônica e, sobretudo, inédita." (Tradução da autora)

25 "La palabra ch'ixi tiene diversas connotaciones: es un color producto de la yuxtaposición, en pequeños puntos o manchas, de dos colores opuestos o contrastados: el blanco y el negro, el rojo y el verde, etc. Es ese gris jaspeado resultante de la mezcla imperceptible del blanco y el negro, que se confunden para la percepción sin nunca mezclarse del todo. La noción ch'ixi, como muchas otras (allqa, ayni) obedece a la idea aymara de algo que es y no es a la vez, es decir, a la lógica del tercero incluido. Un color gris ch'ixi es blanco y no es blanco a la vez, es blanco y también es negro, su contrario." (RIVERA CUSICANQUI, 2010, p. 69)

${ }^{26}$ Nas palavras da autora: "La noción de ch'ixi, por el contrario, equivale a la de "sociedad abigarrada" de Zavaleta, y plantea la coexistencia en paralelo de múltiples diferencias culturales que no se funden, sino que antagonizan o se complementan. Cada una se reproduce a sí misma desde la profundidad del pasado y se relaciona con las otras de forma contenciosa." (RIVERA CUSICANQUI, 2010, p. 70)

27 "O ch'ixi constitui assim uma imagem poderosa para pensar a coexistência de elementos heterogêneos que não aspiram à fusão e que também não produzem um termo novo, superador e englobante." (Tradução da autora)
} 
mundo indígena com seu oposto, sem nunca misturá-lo com ele.

Nessa perspectiva, o baile de los chinos não interessaria como processo de hibridação, mas pela "trama alternativa y subversiva de saberes y de prácticas" 28 (RIVERA CUSICANQUI, 2010, p. 33) que deles se pode depreender, aquilo que resiste à fusão e que dá a ver a multiplicidade de memórias que coabitam nas subjetividades. Uma prática incorporada com raízes profundas na memória ancestral que produz a diferenciação e a singularização como formas de resistência e resiliência. Nesse sentido, destaco o que diz Ailton Krenak sobre a resistência indígena e o que chama de "expansão da subjetividade": "A gente resistiu expandindo a nossa subjetividade, não aceitando essa ideia de que nós somos todos iguais. Ainda existem aproximadamente 250 etnias que querem ser diferentes umas das outras no Brasil, que falam mais de 150 línguas e dialetos." (KRENAK, 2019, p. 15) A oportunidade e a liberdade de fazer escolhas no plano da economia subjetiva que preservem diversidades é apontada como enfrentamento à homogeneização e redução de todas as formas de vida a um modelo civilizatório:

Definitivamente não somos iguais, e é maravilhoso saber que cada um de nós que está aqui é diferente do outro, como constelações. O fato de podermos compartilhar esse espaço, de estarmos juntos viajando não significa que somos iguais; significa exatamente que somos capazes de atrair uns aos outros pelas nossas diferenças, que deveriam guiar o nosso roteiro de vida. Ter diversidade, não isso de uma humanidade com o mesmo protocolo. Porque isso até agora foi só uma maneira de homogeneizar e tirar nossa alegria de estar vivos. (KRENAK, 2019, p. 16)

Não se trataria apenas de pensar a inclusão e valorização de saberes e práticas ancestrais em uma concepção de modernidade que segue se fazendo hegemônica, com sua linearidade positiva rumo a um progresso que se lança sempre para mais adiante. Trata-se de dar o salto para fora dessa lógica, pois como já anotara Benjamin (2007, p. 159) em suas passagens: a crença no progresso é tão mítica quanto a representação do eterno retorno. Rivera Cusicanqui aponta que:

No hay "post" ni "pre" en una visión de la historia que no es lineal ni teleológica, que se mueve en ciclos y espirales, que marca un rumbo sin dejar de retornar al mismo punto. El mundo indígena no concibe a la historia linealmente, y el pasadofuturo están contenidos en el presente: la regresión o la progresión, la repetición o la superación del pasado están en juego en cada coyuntura y dependen de nuestros actos más que de nuestras palabras. El proyecto de modernidad indígena podrá aflorar desde el presente, en una espiral cuyo movimiento es un continuo retroalimentarse del pasado sobre el futuro, un "principio esperanza" o "conciencia anticipante" (Bloch) que vislumbra la descolonización y la realiza al mismo tiempo. La experiencia de la contemporaneidad nos compromete en el presente -aka pacha-y a su vez contiene en sí misma semillas de futuro que brotan desde el fondo del pasado - qhip nayr uñtasis sarnaqapxañani. El presente es escenario de pulsiones modernizadoras y a la vez arcaizantes, de estrategias preservadores del

28 "Trama alternativa e subversiva de saberes e de práticas." (Tradução da autora) 
status quo y de otras que significan la revuelta y renovación del mundo: el pachakuti. El mundo al revés del colonialismo, volverá sobre sus pies realizándose como historia sólo si se puede derrotar a aquellos que se empeñan en conservar el pasado, con todo su lastre de privilegios mal habidos. Pero si ellos triunfan, "ni el pasado podrá librarse de la furia del enemigo", parafraseando a Walter Benjamin ${ }^{29}$ (RIVERA CUSICANQUI, 2010, p. 54-55)

O movimento da história em ciclos que se repetem diz muito sobre nosso presente e sobre aquilo que Benjamin (1985, p. 226) destacava em suas teses: "O assombro com o fato de que os episódios que vivemos no século XX 'ainda' sejam possíveis, não é um assombro filosófico. Ele não gera nenhum conhecimento, a não ser o conhecimento de que a concepção de história da qual emana semelhante assombro é insustentável." A repetição cíclica do passado, entretanto, traz uma contínua abertura da memória que se quer construir no presente, pleno de tensões e disputas constantes, onde estão também os enfrentamentos dos sonhos, inclusive aqueles ponderados e planejados, onde a imaginação da coexistência de mundos se alia às políticas que a tornem possível.

\section{Referências}

BENJAMIN, Walter. "Sobre o conceito de história". In: BENJAMIN, Walter. Magia e técnica, arte e política. Obras escolhidas. Tradução de Sergio P. Rouanet. São Paulo: Brasiliense, 1994, vol. 1.

BENJAMIN, Walter. Passagens. Edição Alemã de Rolf Tiedemann; organização da edição brasileira Willi Bolle; tradução do alemão de Irene Aron; tradução do francês de Cleonice P. B. Mourão. Belo Horizonte: Editora UFMG; São Paulo: Imprensa Oficial do Estado de São Paulo, 2007, 1‥ reimpressão.

BERGSON, Henry. Matéria e memória. Ensaio sobre a relação do corpo com o espírito. Tradução de Paulo Neves. São Paulo: Martins Fontes, 2000.

\footnotetext{
29 “Não há 'pós' nem 'pré' em uma visão da história que não é linear nem teleológica, que se move em ciclos e espirais, que marca um rumo sei deixar de retornar ao mesmo ponto. 0 mundo indígena não concebe a história linearmente, e o passado-futuro estão contidos no presente: a regressão ou a progressão, a repetição ou a superação do passado estão em jogo em cada conjuntura e dependem de nossos atos mais que de nossas palavras. $O$ projeto de modernidade indígena poderá aflorar desde o presente, em uma espiral cujo movimento é uma contínua retroalimentação do passado sobre o futuro, um 'princípio esperança' ou 'consciência antecipatória' (Bloch) que vislumbra a descolonização e a realiza ao mesmo tempo. A experiência da contemporaneidade nos compromete no presente - aka pacha - e, por sua vez, contém em si mesma sementes de futuro que brotam do fundo do passado - qhip nayr uñtasis sarnaqapxañani. O presente é cenário de pulsões modernizadoras e ao mesmo tempo arcaizantes, de estratégias conservadoras do status quo e de outras que significam a revolta e renovação do mundo: o pachakuti. O mundo ao contrário do colonialismo, voltará sobre seus pés, realizando-se como história somente se conseguirem se derrotar àqueles que se empenham em conservar o passado, com todo seu lastro de privilégios mal ganhos. Mas se eles triunfam, 'nem o passado poderá libertar-se da fúria do inimigo', parafraseando Walter Benjamin." (Tradução da autora)
} 
CANLINI, Néstor García. Culturas híbridas. Tradução de Heloísa P. Cintrão. SP: EDUSP, 2003.

DIDI-HUBERMAN, Georges. Ante el tiempo. Historia del arte y anacronismo de las imágens. Tradução de Antonio Oviedo. Buenos Aires: Adriana Hidalgo, 2011.

DIDI-HUBERMAN, Georges. Sobrevivência dos vaga-lumes. Tradução de Vera Casa Nova e Márcia Arbex. BH: UFMG, 2011a.

FOUCAULT, Michel. O corpo utópico, as heterotopias. Tradução de Salma T. Muchail. São Paulo: n-1 Edições, 2013.

GUATTARI, Felix e ROLNIK, Suely. Micropolítica. Cartografais do desejo. Petrópolis: Vozes, 1996.

KRENAK, Ailton. Ideias para adiar o fim do mundo. São Paulo: Companhia das Letras, 2019.

MERCADO MUÑOZ, Claudio. "Ritualidades en conflicto: los bailes chinos y la Iglesia Católica en Chile Central". Rev. music. chil., Santiago, v. 56, n. 197, p. 3976, janeiro 2002.2 Disponível em:

https://scielo.conicyt.cl/scielo.php?script=sci arttext\&pid=S0716-

$27902002019700003 \&$ Ing=es\&nrm=iso Acesso em: 16/11/2020.

RIVERA CUSICANQUI, Silvia. Ch'ixinakax utxiwa. Una reflexión sobre prácticas y discursos descolonizadores. Buenos Aires: Tinta Limón, 2010.

SHECHNER, Richard. "What is performance?". In: Perfomance Studies: an introduction. New York/Londres: Routledge, 2006, pp. 28-51. Tradução de R.L.Almeida. Publicado sob licence creative commons, classe 3, Abril 2011, n.p. Disponível em: https://files.cercomp.ufg.br/weby/up/378/o/O QUE EH PERF SCHECHNER.pdf Acesso em: 20/11/2020

TAYLOR, Diana. O arquivo e repertório. Performance e memória cultural nas Américas. Tradução de Eliana Reis. BH: UFMG, 2013.

VICUÑA, Cecília. Sabor a mí. Devon, UK: Beau Geste Press, 1973.

VICUÑA, Cecília. PALABRARmás. Santiago de Chile: RIL editores, 2005.

VICUÑA, Cecília. PALAVRARmás. Tradução de Ricardo Corona. Curitiba: Medusa, 2017.

\section{Filmografia}

BOLOGNESI, Luiz. Guerras do Brasil.Doc, 2018. Série documental em 5 episódios. Netflix. Episódio1: As guerras da conquista. Disponível em: https://www.youtube.com/watch?v=VeMISgnVDZ4 (Acesso 23/11/2020)

VICUÑA, Cecília. Tugar Tugar, salir a buscar el sentido perdido. Dezembro de 2011. Duração: $30: 26$

\section{Páginas web}

$<$ https://www.chimuchina.org/>

$<$ http://oysi.org/>

<https://ich.unesco.org/es/RL/el-baile-chino-00988> 
Recebido em: 08/10/2020

Aceito em: 12/11/2020 